\title{
Review: Chemical Methodology in Entomology and Ecology
}

\author{
Millar, J.G. and Haynes, K.F. 1998: Methods in Chemical Ecology. Chapman \& Hall, New York. Pp. \\ 390.
}

There can't be too many entomologists who haven't seen or used the "Journal of Chemical Ecology", but I dare say few are familiar with the wide variety of tools and methods nowadays available to scientists researching natural products of ecological importance. This book, edited by Jocelyn G. Millar of the University of California, Department of California, Riverside and Kenneth F. Hayes of the University of Kentucky, Department of Entomology, Lexington, is subtitled "Chemical Methods". A black and white photograph of moths on some vegetation and part of the formula of an organic molecule adom the hard cover. Unfortunately the reader never finds an explanation for that cover illustration nor who Audrey Bingham Millar was and why the book was dedicated to her.

Of the 10 authors who contributed to this book of nearly 400 pages, eight are scientists based in the U.S.A. and two are from Japanese laboratories. Perhaps this explains why in the citations publications of European researchers are underrepresented and the contribution Tony Swain has made to the development of Chemical Ecology (Simmonds 1998) is totally ignored. Even more irritating is the fact that in the appended list of ca. 50 supply companies no more than three with an address outside the U.S.A. are included. There is no doubt that such a list can be extremely useful to the practicioner of Chemical Ecology, but I do not believe for one second that workers in Europe and elsewhere in the world could not find suitable supply companies closer to their places of activity than the ones with U.S.A. addresses in the list. Obviously the book is aimed at an American readership.

The editors say in their Preface that a working definition of Chemical Ecology might be "the study of the structure, function, origin, and significance of naturally occurring compounds that mediate inter- and intraspecific interactions between organisms." If that statement truly describes the discipline of Chemical Ecology, then no book of nine chapters, no matter how well written or presented, can possibly do justice to all the methods used in this field of study. The editors are aware of this and for that reason must have decided to produce a companion volume on bioassays to the one under discussion.

This Chemical Methods volume starts with a chapter by J.G. Millar and J.J. Sims on extraction, fractionation, and purification of compounds and continues with chapters covering identification and quantification. Well structured and written in clear language, the first chapter provides a good introduction to biologically active extracts and how to obtain some of them. Some line-drawings depicting apparatus and devices are included, but the size of the gadgets has to be guessed as no scale is provided. Specific chapters are devoted to the various liquid- (J.G. Millar) and gaschromatograph- ical methods (R.R. Heath and B.D. Dueben), but why the important techniques of countercurrent chromatography and capillary electrophoresis have been so poorly covered is not clear. Surprising, too, is that the standard Folch phospholipid extraction method receives no mention. The chapters could have benefitted from more specific examples, but the inclusion of 'troubleshooting guides' is a positive feature.

Mass Spectrometry is dealt with in Chapter 4 by F.X. Webster, J.G. Millar and D.J. Kiemle on only 25 pages. Although the basics of mass spectrometry are explained and some ionization methods are covered, one might have expected a more comprehensive treatment of this powerful and important technique. Once again, the inclusion of specific examples would have benefitted those readers still doubtful as to whether in their own research mass spectrometry has a place. In Chapter 5, Webster and Kiemle explore 'Structure Elucidation by NMR', but since this field is growing and progressing so rapidly, one wonders how much of the specifics presented in this chapter will be of relevance in years to come. Mass spectrometry is certainly indispensable for the chemical analysis of nanogram and sub-nanogram quantities of compounds whose structures are already known, but NMR now enables the determination of the structures of completely new compounds. Whether, however, an 'ordinary' ecologist, who has read this chapter, will be brave enough to employ NMR without the help of a specialist is more than doubtful. The chapter on NMR is certainly not a user's 'instruction manual'. One of the rare printing errors of this book has crept in on page 164, where it said TOSCY instead of TOCSY (=totally correlated spectroscopy). Use of infrared and UVspectroscopy forms the topic of Chapter 6 by W.S.Leal. Not at all a comprehensive review of the field, the chapter of 21 pages nonetheless provides a good working knowledge of the techniques and contains in tabulated form many very useful examples of Vapour-Phase IR-group, $\mathrm{OH}$-, and CO-stretching frequencies. Chapter 7 by A.B. Attygalle gives valuable information on microchemical techniques and providing more than just a list of different methods, is perhaps the most thorough of all of the book's chapters. Even the scale, i.e. the dimensions of the illustrated reaction tubes are given. Most of the methods mentioned by K. Mori in Chapter 8 on "Separation of Enantiomers and Determination of Absolute Configuration" have been covered in the preceding chapters, but Mori's article shows how useful certain methods can be in elucidating the configurations and formulae of a wide range of insect substances, chiefly pheromones.

The final chapter, written by L.B. Bjostad, is titled "Electrophysiological Methods" and, thus, hardly a topic suited for a book claiming on the cover to deal with Chemical Meth- 
ods. Nevertheless, having once myself written an article on electrophysiological methods aimed at general entomologists (Meyer-Rochow 1981), I am naturally quite happy about the inclusion of this chapter. Objectively, however, one might question if a chapter dealing with EDX-analyses (= energy dispersive X-ray spectroscopy) or radioimmuno-asseys or even immunocytochemical methods might not have been a better choice to conclude this book with. As it is, the basics of the electro-physiological recording techniques are well covered by Bjostad, but more illustrations of electrode designs, electrode holders, preparations would have been useful. Why for details on sharpening tungsten electrodes (even now so useful in recordings from olfactory receptors), reference is twice (on pages 345 and 362) made to that old 2-page SCIENCE-paper by Hubel (1957) without briefly describing the method, is hard to understand. Also, including websites of data-aquisition systems without explaining what is actually available in that area is perhaps not wholly satisfactory. Even if the chapter confines itself purely to recording methodology, signal processing has made such incredible advances in the last few years that one reference to a 1980-paper (Bjostad \& Roelofs 1980) could hardly suffice. The lack of a paragraph on troubleshooting is an unfortunate ommission as it could have helped the beginning electrophysiologist. Finally, why several references to insect haemolymph compositions are given in the text, but not included in the accompanying table and why certain examples of EAG-recordings were chosen to illustrate the article, but contain neither time nor voltage scale, is difficult to understand.

So, what to make of this book? Since, in the editors' own words, "the basics have not been covered again here", the book has clearly not been written for the beginner. But is it a book for experts then? I do not think so, because many highly specific methods have deliberately been left out, mathematical, physical, and chemical equations are kept to a minimum, and technological developments, still considered too experimental in nature, do not feature. It is perhaps a book for folk like myself, with some experience and knowledge in certain of the techniques covered, but not all of them. It is for people who are thankful for information on techniques and methods they may wish to employ but don't know too much about. Yet, one of the greatest drawbacks of this volume and one of the reasons why it would be of limited use to the average entomologist is the index at the end of the book. Dozens of insects and their compounds are mentioned in the various articles (Chapter 8 in particular), but none of the insects can be looked up as insect names are not listed in the index. Names of authors whose works were cited also do not feature in an index. Readers wanting to look up 'antioxidant', or 'methylation', or 'pheromone' search in vain: the index does not contain these and many other important entries. The order in which some of the words appear in the index is frequently not even alphabetic. For example under 'HPLC detectors' the reader finds 'diode array detector' and 'solvent' below 'UV detectors' and 'Variable wavelength'. Likewise,'COSY' and 'HECTOR', listed under NMR, follow words starting with " $\mathrm{t}$ ". It must be held against the editors, who otherwise have tried to produce a worthwhile and informative book, that not more attention has been paid to the index, for talking about myself, I might have considered purchasing the book had it had an index in which I could have looked up the names of some insects.

Bjostad, L.B. \& Roelofs, W.L. 1980: An inexpensive electronic device for measuring electroantennogram responses to sex pheromone components with a voltmeter. - Physiol. Entomol. 5: 309-314.

Hubel, D.H. 1957: Tungsten microelectrode for recording from single units. - Science 125: 549-550.

Meyer-Rochow, V.B. 1981: Electrophysiological studies on the insect eye. - N. Zld. Entomologist 7: 296-304.

Simmonds, M.S.J. 1998: Chemoecology: the legacy lefy by Tony Swain. - Phytochemistry 49: 1183-1190.

V.B. Meyer-Rochow 